\title{
A comparison of the keypeck and treadlepress operants in the pigeon: Differential- reinforcement-of-low-rate yoked variable-interval schedule
}

\author{
W. KIRK RICHARDSON \\ Georgia State University, Atlanta, Georgia 30303
}

\begin{abstract}
Earlier investigations have indicated that the treadlepress response of the pigeon may not be as sensitive as the keypeck to the differential reinforcement of long interresponse times. This study tested the sensitivity of each operant under a multiple differential-reinforcement-of-low-rate yoked variable-interval schedule that approximately equated reinforcement rate in the two schedule components. Three of four pigeons had much higher response rates in the variable-interval component for both operants, while one pigeon responded at the same rate in both components for both operants. These results showed that both the treadlepress and the keypeck response are similarly affected by the differential reinforcement of long interresponse times.
\end{abstract}

The differential-reinforcement-of-low-rate (DRL) schedule of reinforcement is unique among the simple schedules of reinforcement in that there is a negative correlation between response rate and reinforcement rate under typical laboratory conditions (Richardson \& Loughead, 1974; Wilson \& Keller, 1953). The negative correlation is a result of the schedule requirement that only responses with an interresponse time (IRT) greater than some specified minimum (the schedule parameter) are followed by reinforcement. In 1970, Kramer and Rilling concluded that pigeons were "decidely inferior" to rats, monkeys, and humans in terms of the percentage of reinforced responses under the DRL schedule. Hemmes (1975) reported that pigeons performed at a much higher level when the response required was treadlepressing rather than keypecking, the traditional operant for pigeon experimentation. Indeed, Hemmes found a higher percentage of reinforced responses at a DRL value of $35 \mathrm{sec}$ using the treadle operant than at a DRL value of $14 \mathrm{sec}$ using the key operant. However, Hemmes did not present IRT or response probability distributions, so the temporal distribution of responses as a function of the operant could not be determined.

Richardson and Clark (1976) compared the keypeck and the treadlepress operants under the DRL schedule over a range of DRL values and found the percent of reinforced responses was usually higher for the treadlepress response than for the keypeck response. The IRT

I wish to thank the computer center of Georgia State University for providing the computer time and the computer programs necessary to obtain and analyze the data. Reprints may be obtained from W. Kirk Richardson, Psychology Department, Georgia State University, University Plaza, Atlanta, Georgia 30303. distributions showed that the higher reinforcement rate on the treadle was due to many IRTs that greatly exceeded the DRL value, while there were very few IRTs greatly exceeding the DRL value for the keypeck operant. However, response probability (IRTs per opportunity; Anger, 1956) distributions showed a more precise temporal discrimination for the keypeck operant than for the treadlepress operant; thus, the direction of the effect of the operant on the DRL performance of the pigeon depends on the dependent variable. Percentage of reinforced response is lower but temporal discrimination is sharper for the keypeck operant than for the treadlepress operant so that, in one sense, the keypeck may be more sensitive to the DRL requirement. Pigeons obtained more reinforcements when treadlepressing by spreading IRTs over a wide range, not by localizing them just above the DRL values in a manner indicating a temporal discrimination. Although very long IRTs are always reinforced under the DRL schedule, there is a cost for long IRTs in a reduction of reinforcement rate as compared to IRTs that just exceed the DRL value. A possible interpretation of these data is that the pigeon's treadlepress response is not sensitive to the differential reinforcement of long IRTs; that is, the IRT distribution is controlled by other factors such as the rate and distribution of reinforcement.

A method of measuring the effectiveness of the differential reinforcement of long IRTs specified by the DRL schedule is to compare responding under the DRL schedule with a yoked variable-interval (VI) schedule having the same rate and distribution of reinforcement as the DRL schedule but with no formal specification of which IRTs may be reinforced. Richardson (1973, 1976) found a higher response rate under the yoked VI 
schedule than under the DRL schedule for pigeons when keypecking was the response. This experiment compared the treadlepress and keypeck responses under the DRL yoked VI schedule.

\section{METHOD}

\section{Subjects}

Four adult racing homing pigeons (P1, P2, P3, P4) maintained at $75 \%$ of their free-feeding weights served as subjects. All pigeons had previously been trained with the keypeck response under the multiple (mult) DRL yoked VI schedule used in this experiment with DRL values ranging from .5 to $25 \mathrm{sec}$ (Group 1 of Richardson, 1976).

\section{Apparatus}

Subjects were tested in four identical operant chambers with inside dimensions of $52 \mathrm{~cm}$ long, $36 \mathrm{~cm}$ wide, and $33 \mathrm{~cm}$ high. The response panel in each chamber had a key hole $2.5 \mathrm{~cm}$ in diameter centered $22 \mathrm{~cm}$ above the floor. The response key was a translucent Plexiglas paddle. The rear surface of the paddle was painted flat black except for a circle $1 \mathrm{~cm}$ in diameter that was centered behind the key hole and transilluminated from the rear with green light. A force of 15 to $20 \mathrm{~g} \mathrm{(.15} \mathrm{to} .20 \mathrm{~N})$ with an excursion of $1 \mathrm{~mm}$ was required to operate the response key. A wooden treadle $5 \mathrm{~cm}$ wide and $6.5 \mathrm{~cm}$ long extending from a box $15.5 \mathrm{~cm}$ long, $6 \mathrm{~cm}$ wide, and $8 \mathrm{~cm}$ high was placed in a corner of the chamber with the back of the treadle box against the response panel. The treadle was $3 \mathrm{~cm}$ above the floor. Two stimulus lamps were mounted on the upper surface of the box, and the entire apparatus was painted gray. A force of 30 to $35 \mathrm{~g}$ with an excursion of $10 \mathrm{~mm}$ was required to operate the treadle.

The reinforcer was one 45-mg Noyes pigeon pellet delivered to a Scientific Prototype tray located $7.7 \mathrm{~cm}$ below and $5 \mathrm{~cm}$ to the left of the response key. A $28-\mathrm{V}$ shielded bulb located $.5 \mathrm{~cm}$ above the food tray illuminated the tray for $1 \mathrm{sec}$ following delivery of the reinforcer. Houselights consisted of two 28-V bulbs behind a Plexiglas screen placed across the top of the response panel. An $85-\mathrm{dB}$ re: $20 \mu \mathrm{N} / \mathrm{m}^{2}$ white masking noise was continuously present in the test chambers and a blower system was in operation to provide ventilation. An IBM 1800 data acquisition system located in an adjacent room controlled the experiment and recorded responses. Responses to either operadum with IRTs less than $50 \mathrm{msec}$ were not counted.
\end{abstract}

\section{Procedure}

A mult DRL yoked VI schedule was used. Under this schedule, each session was divided into two parts (components) of equal duration. During the first component, which was signaled by a discriminative stimulus, reinforcement was programmed according to a DRL 10-sec schedule. During the second component, signaled by a different discriminative stimulus, reinforcement was programmed according to a VI schedule. The interreinforcement intervals programmed by the VI schedule were the interreinforcement intervals the pigeon generated during the preceding DRL component; that is, the programmed interreinforcement intervals of the VI schedule component were yoked to the actual interreinforcement intervals of the preceding DRL schedule component. For example, a red keylight was present during the first half $(25 \mathrm{~min})$ of the session and reinforcement was delivered according to a DRL 10 -sec schedule. During the second half $(25 \mathrm{~min})$ of the session, a green keylight was present and reinforcement was delivered according to a yoked VI schedule. If the first reinforcement during the DRL component occurred $50 \mathrm{sec}$ after the beginning of the session and the second reinforcement occurred $93 \mathrm{sec}$ later, then the first two programmed interreinforcement intervals of the yoked VI schedule were 50 and $93 \mathrm{sec}$.
With the keys covered by metal plates, the pigeons were shaped to press the treadle, then given two sessions of reinforcement for each response on the treadle for 40 reinforcements per session. The treadlepress response was then tested daily for 40 sessions under the mult DRL 10-sec yoked VI schedule of reinforcement. The white stimulus lamp on the treadle box was illuminated during the DRL component, and the red stimulus lamp was illuminated during the yoked VI component.

After 40 sessions of testing the treadle response, the treadles were removed and the keys were uncovered. The pigeons were tested under the mult DRL 10 -sec yoked VI schedule of reinforcement for 24 sessions without any preliminary training. The keylight was green during the DRL component and red during the VI component. In the key condition, there was a 10- to 15-sec period between the DRL component and the VI component, during which the keylight and houselight were extinguished.

All pigeons were observed frequently during the treadle condition and only one pigeon, P3, was ever observed to peck the treadle. This pigeon pecked the treadle only infrequently and was never observed to receive a reinforcement immediately after pecking the treadle.

The DRL schedule reinforced every response terminating an IRT equal to or greater than $10 \mathrm{sec}$, with IRTs measured as the time from the beginning of the session to the first response and thereafter as the time between two successive responses. Under the VI component, reinforcement was delivered for the first response that occurred after an interreinforcement interval had elapsed. The following interreinforcement interval was measured from the delivery of the reinforcer.

\section{RESULTS AND DISCUSSION}

Figure 1 presents the response rates during each component of the multiple schedule over blocks of two sessions. Three of the four pigeons developed higher response rates during the VI component, while $\mathrm{P} 4$ responded at the same rate in both components for both the key and the treadle response. Means of the last four sessions under each condition are presented in Table 1 for reinforcers per hour and relative response rate (VI response rate/VI response rate plus DRL response rate). P4 had the same relative response rate for both operants, while the other pigeons had higher relative rates for the key response.

Reinforcers per hour were identical for the DRL and VI components when the response was keypecking but were higher for the DRL schedule when the response was treadlepressing. The reinforcer rate was about the same for both operants under the DRL schedule except for P4, where the reinforcer rate was much higher for the treadle than for the key response. This shows that in the absence of any temporal discrimination, a pigeon may receive many more reinforcers with a treadle response than with a key response; thus, a higher reinforcer rate cannot be used as a measure of the degree of temporal control of two operants. The higher response rate to the key, even though the key reinforcer rate was lower in the case of $\mathrm{P} 4$, shows that a difference in response rate between two operants cannot be taken as a measure of temporal control either. This is consistent with arguments made by Richardson and Clark (1976) based on IRT relative frequency distributions and re- 


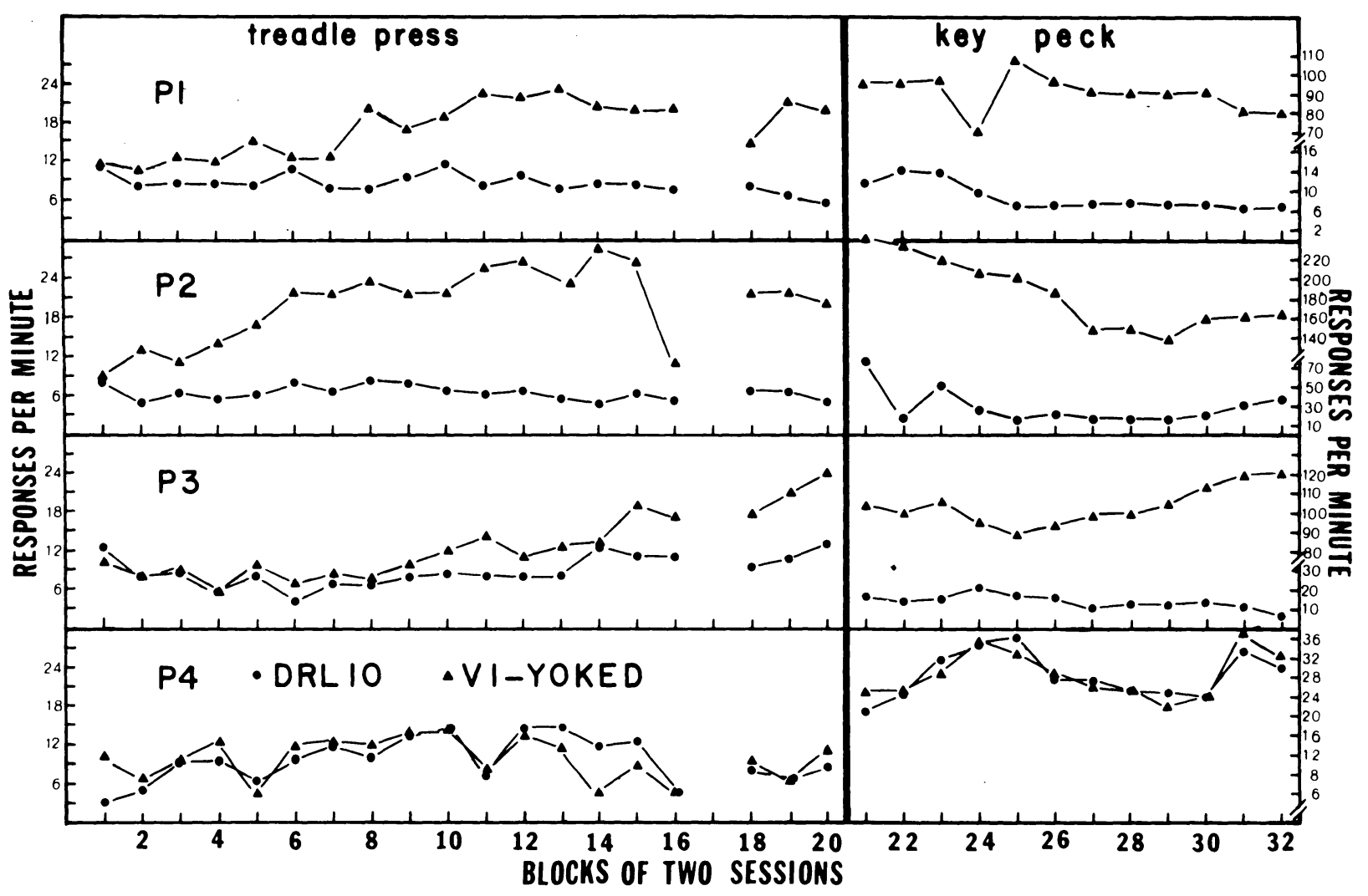

Figure 1. Response rate as a function of blocks of two sessions for individual pigeons under the mult DRL yoked VI schedule with the treadlepress response (left panels) and the keypeck responses (right panels). The data for Block 17 were lost. The treadlepress response rate is presented on the left ordinate and the keypeck is presented on the right ordinate.

sponse probability distributions. The clear difference between the response rates in the two components for the other three pigeons shows that the treadle response, as well as the key response, is sensitive to the presence or absence of a formal IRT requirement as programmed by the DRL schedule:

The yoking procedure did not equate the two schedules for reinforcer rate when the response was treadlepressing. The expected effect of the lower VI reinforcer rate would be to reduce the response rate during the VI schedule. If the reinforcer rates had

Table 1

Relative Response Rates and Reinforcer Rates

\begin{tabular}{lrrrrrr}
\hline & \multirow{2}{*}{$\begin{array}{c}\text { Relative } \\
\text { Response Rate }\end{array}$} & \multicolumn{3}{c}{ Reinforcers Per Hour } \\
\cline { 3 - 7 } & Key & Treadle & DRL & VI & DRL & VI \\
\hline P1 & .92 & .77 & 204.0 & 204.0 & 202.2 & 180.6 \\
P2 & .82 & .78 & 117.0 & 117.0 & 163.2 & 146.4 \\
P3 & .93 & .66 & 157.8 & 157.8 & 114.6 & 107.4 \\
P4 & .52 & .53 & 3.6 & 3.6 & 95.3 & 76.8 \\
\hline
\end{tabular}

Note-The data are means over the last foilr sessions. actually been equated by having a higher VI reinforcer rate and this had caused the VI response rate to increase, then the treadle relative response rates would be increased and might have been as high for the treadle response as for the key response. The reason the yoking procedure failed to equate for reinforcer rate can be found in the IRT distributions for the VI component, shown in Table 2. The key response had most IRTs less than $1 \mathrm{sec}$, with a very small proportion being greater than $3 \mathrm{sec}$. The treadle IRTs were, in contrast, spread over a wide range, with only a small proportion less than $1 \mathrm{sec}$. This implies that the reinforced IRTs were much longer for the treadle than for the key response. As the timing of an interreinforcer interval did not begin until the previous reinforcer was delivered, there was a cumulative effect of the time difference between when a reinforcer became available and when that reinforcer was delivered. This bias could be reduced by timing the interreinforcer intervals of the VI schedule from reinforcer availability to reinforcer availability, so any difference between when a reinforcer became available and when the reinforcer was delivered would not be cumulative. 
Table 2

Relative Frequency Distributions of IRTs for the VI Component

\begin{tabular}{|c|c|c|c|c|c|c|c|c|}
\hline \multirow{2}{*}{$\begin{array}{l}\text { Class } \\
\text { Inter- } \\
\text { val }\end{array}$} & \multicolumn{2}{|c|}{ P1 } & \multicolumn{2}{|c|}{ P2 } & \multicolumn{2}{|c|}{ P3 } & \multicolumn{2}{|c|}{ P4 } \\
\hline & K & $\mathrm{T}$ & K & $T$ & K & $\mathrm{T}$ & $\mathrm{K}$ & $\mathrm{T}$ \\
\hline 1 & 82.7 & 26.3 & 97.4 & 35.0 & 97.4 & 21.4 & 49.0 & 1.3 \\
\hline 2 & 11.6 & 26.4 & 1.3 & 29.8 & $(2.6)$ & 20.4 & 10.3 & 23.4 \\
\hline 3 & 1.3 & 13.6 & (1.3) & 9.7 & & 24.5 & 17.3 & 21.5 \\
\hline 4 & $(4.4)$ & 8.9 & & 5.7 & & 13.3 & 8.4 & 10.2 \\
\hline 5 & & 5.8 & & 3.3 & & 6.0 & 6.3 & 6.5 \\
\hline 6 & & 4.9 & & 3.1 & & 4.1 & 4.0 & 4.4 \\
\hline 7 & & 4.4 & & 2.7 & & 3.1 & 2.2 & 4.5 \\
\hline 8 & & 2.7 & & 2.3 & & 2.5 & 1.1 & 3.4 \\
\hline 9 & & 1.9 & & 1.9 & & 1.6 & (1.4) & 3.5 \\
\hline 10 & & 1.5 & & 1.2 & & 1.1 & & 2.3 \\
\hline 11 & & $(3.5)$ & & (1.2) & & $(2.0)$ & & 2.3 \\
\hline 12 & & & & & & & & 2.5 \\
\hline 13 & & & & & & & & 1.7 \\
\hline 14 & & & & & & & & 2.2 \\
\hline 15 & & & & & & & & 1.1 \\
\hline 16 & & & & & & & & 1.1 \\
\hline 17 & & & & & & & & (8.3) \\
\hline
\end{tabular}

Note-All percentages of 1 or larger are given. The data are means over the last five sessions. The class interval number is the nominal upper limit (in seconds) of a 1-sec width interval; for example, Interval 5 includes all IRTs from 4.00 to $4.99 \mathrm{sec}$. The last number in each column (in parentheses) is the cumulative total for that and larger class intervals. $K=k e y, T=$ treadle.

\section{REFERENCES}

ANger, D. The dependence of interresponse times upon the relative reinforcement of different interresponse times. Journal of Experimental Psychology, 1956, 52, 145-161.

Hemmes, N. S. Pigeon's performance under differential reinforcement of low rate schedules depends upon the operant. Learning and Motivation, 1975, 6, 344-357.

Kramer, T. J., \& Rilling, M. Differential reinforcement of low rates: A selective critique. Psychological Bulletin, 1970, 4, 225-254.

Richardson, W. K. A test of the effectiveness of the differentialreinforcement-of-low-rate schedule. Journal of the Experimental Analysis of Behavior, 1973, 20, 285-391.

RICHARDSON, W. K. The sensitivity of the pigeon's keypeck to the differential reinforcement of long interresponse times. Animal Learning \& Behavior, 1976, 4, 231-240.

RICHARDSON, W. K., \& ClARK, D. B. A comparison of the key-peck and treadle-press operants in the pigeon: Differentialreinforcement-of-low-rate schedule of reinforcement. Journal of the Experimental Analysis of Behavior, 1976, 26, 237-256.

Richardson, W. K., \& Loughead, T. E. Behavior under large values of the differential-reinforcement-of-low-rate schedule. Journal of the Experimental Analysis of Behavior, 1974, 22, 121-129.

Wilson, M. P., \& KelleR, F. S. On the selective reinforcement of spaced responses. Journal of Comparative and Physiological Psychology, 1953, 46, 190-193.

(Received for publication January 17, 1979.) 